\title{
Night vision in a case of vitamin A deficiency due to malabsorption
}

\author{
IDO PERLMAN, ${ }^{1}$ DAVID BARZILAI, ${ }^{2}$ TAMAR HAIM,${ }^{3}$ AND ALFRED SCHRAMEK ${ }^{4}$ \\ From the 'Department of Physiology and Biophysics, Faculty of Medicine, Technion, Haifa; \\ the ${ }^{2}$ Department of Internal Medicine, Rambam Medical Center, Haifa; the ${ }^{3}$ Department of \\ Ophthalmology, Rambam Medical Center, Haifa, and the ${ }^{4}$ Department of Surgery, \\ Rambam Medical Center, Haifa, Israel
}

SUMMARY Night vision was tested electroretinographically and psychophysically in a vitamin A deficient patient before and after therapy. Vitamin A deficiency resulted from malabsorption due to a jeujunoileal bypass operation. Before therapy the patient had severely reduced cone and rod function. After the reversal operation, accompanied by 5 injections of a total of 500000 units of vitamin A, complete recovery of cone and rod functions was observed within 7 months. Shortly after therapy rod sensitivity reached the normal level, while the time course of rod adaptation remained slower than normal and the dark-adapted electroretinographic (ERG) responses were subnormal. At later stages the ERG responses reached normal amplitudes but rod adaptation stayed slow. Only after 7 months did night vision reach the normal level with regard to the time course of rod adaptation, rod sensitivity, and ERG responses.

Disturbances in night vision have long been associated with vitamin A deficiency. Numerous cases of night blindness have been reported to arise from malnutrition, ${ }^{12}$ malabsorption of vitamin $A,,^{3-6}$ or impaired vitamin A metabolism due to liver disease.$^{6-8}$ Direct evidence of the relationship between vitamin $A$ and vision was demonstrated in humans maintained on vitamin A deficient diet. ${ }^{10}$ These subjects suffered from a progressive loss of both rod and cone sensitivity to light until a mild night blindness had been established.

In most of the above cases of clinically and experimentally induced vitamin A deficiency retinal function recovered close to the normal level after oral vitamin A therapy..$^{3-10}$ In some of the experimentally induced cases of vitamin A deficiency recovery was observed within hours. ${ }^{9}$ In one case of vitamin A deficiency due to malabsorption recovery of rod function was observed after 3 days of oral therapy. ${ }^{5}$ However, the recovery of night vision in most patients suffering from cirrhosis of the liver or malabsorption required large dosage of vitamin $\mathrm{A}$ administered daily for months. ${ }^{348}$ After discontinuance of therapy this improvement was only partly maintained. ${ }^{3}$ Reduction

Correspondence to Ido Perlman PhD, Department of Physiology and Biophysics, Faculty of Medicine, Technion, Haifa, Israel. in retinal function due to vitamin A deficiency and its recovery following vitamin A therapy was also demonstrated experimentally in rats. ${ }^{11-14}$

In this study we evaluated electroretinographically (ERG) and psychophysically the retinal function of one vitamin A deficient patient. Her deficiency resulted from malabsorption due to surgically performed jeujunoileal bypass. ${ }^{45}$ After reversal of the operation and minimal intramuscular administration of vitamin A her retinal function recovered completely. However, the time course of the recovery of the psychophysically determined dark adaptation curve differed significantly from that of the ERG responses.

\section{Case report}

A 58-year-old white woman was admitted to hospital on 30 March 1981 due to diarrhoea, weakness, and reduced visual function, especially at night. Suffering from morbid obesity, the patient underwent a jeujunoileal bypass operation (end to side) about 11 years prior to admission (20 January 1970). After the operation she lost about $26 \mathrm{~kg}$ of body weight (from 138 down to $112 \mathrm{~kg}$ ). On admission laboratory tests showed total bilirubin $3-3 \cdot 4 \mathrm{mg} / \mathrm{dl}(51-58 \mu \mathrm{mol} / \mathrm{l})$ 
(normal $0-1 \cdot 2 \mathrm{mg} / \mathrm{dl}(0-21 \mu \mathrm{mol} / \mathrm{l})$, direct bilirubin $0 \cdot 8-1 \cdot 2 \mathrm{mg} / \mathrm{dl}(14-21 \mu \mathrm{mol} / \mathrm{l})$ (normal $0-0 \cdot 3 \mathrm{mg} / \mathrm{dl}$ $(0-5 \mu \mathrm{mol} / \mathrm{l})$ ), alkaline phosphatase $159-212 \mu \mathrm{g} / \mathrm{ml}$ (159-212 mg/l) (normal 60-230 $\mu \mathrm{g} / \mathrm{ml})$, SGOT 17-27 $\mu \mathrm{g} / \mathrm{ml}(17-27 \mathrm{mg} / \mathrm{l})($ normal 5-45 $\mu \mathrm{g} / \mathrm{ml}(5-45 \mathrm{mg} / \mathrm{l})$ ), total protein $6 \cdot 3 \mathrm{~g} / \mathrm{dl}(63 \mathrm{~g} / \mathrm{l})($ normal $6 \cdot 5-8 \cdot 5 \mathrm{~g} / \mathrm{dl}$ $(65-85 \mathrm{~g} / \mathrm{l}))$, albumin $3 \cdot 7 \mathrm{~g} / \mathrm{dl}(37 \mathrm{~g} / \mathrm{l})$ (normal $3 \cdot 2-5 \cdot 0$ $\mathrm{g} / \mathrm{dl}(32-50 \mathrm{~g} / \mathrm{l}))$, globulin $2.6 \mathrm{~g} / \mathrm{dl}(26 \mathrm{~g} / \mathrm{l})$ (normal $2 \cdot 5-4 \cdot 5 \mathrm{~g} / \mathrm{dl}(25-45 \mathrm{~g} / \mathrm{l}))$, uric acid $7 \cdot 0 \mathrm{mg} / \mathrm{dl}(1 \cdot 2$ $\mathrm{mmol} / \mathrm{l}$ ) (normal 3.0-7.5 mg/dl $(0.5-1.2 \mathrm{mmol} / \mathrm{l})$ ), creatinine $1.2 \mathrm{mg} / \mathrm{dl}(106 \mu \mathrm{mol} / \mathrm{l})$ (normal $0 \cdot 7-15$ $\mathrm{mg} / \mathrm{dl}(62-1326 \mu \mathrm{mol} / \mathrm{l})$ ), sodium $146 \mathrm{mmol} / \mathrm{l}$ (normal $135-150 \mathrm{mmol} / \mathrm{l}$ ), potassium $2 \cdot 6-4 \cdot 0 \mathrm{mmol} / \mathrm{l}$ (normal $3 \cdot 5-5 \cdot 0 \mathrm{mmol} / \mathrm{l})$, carotene 31 units/dl (310 units/l) (normal above 100 units/dl (1000 units/l).

Malabsorption of lipid soluble vitamins ${ }^{4}$ was suspected, and therefore a Schilling test was performed. The test result, $3 \%$, was pathologically low and could not be elevated by the addition of intrinsic factor. The patient received 100000 units of vitamin A intramuscularly once a week. She received a total of 500000 units of vitamin A in 5 injections. On 8 May 1981 she underwent surgery, with reanastomosis of the jeujunoileal bypass and gastric partitioning. An operative liver biopsy was taken, which showed marked signs of fatty liver and postnecrotic cirrhosis. Carotene measurement on 1 November 1981 revealed a normal level of 127 units/dl (1270 units/l).

\section{ELECTRORETINOGRA PHY}

Full field ERG responses were recorded by Perlman and Haim's methods. ${ }^{15}$ Briefly, the ERG was evoked by a $1 \mathrm{~ms}$ flash, the intensity of which was controlled by 'neutral' density filters. Full field illumination was achieved by using a contact lens electrode that contained a -100 dioptre lens which dispersed the light stimulus. The ERG was first recorded in the light adapted state with background illumination of 11 foot-lamberts $\left(38 \mathrm{~cd} / \mathrm{m}^{2}\right)$. After turning off the background light the patient was allowed to darkadapt for 25 minutes before the ERG responses evoked by stimuli of different intensities were recorded.

\section{DARK ADAPTOMETRY}

The time course of threshold recovery in the dark

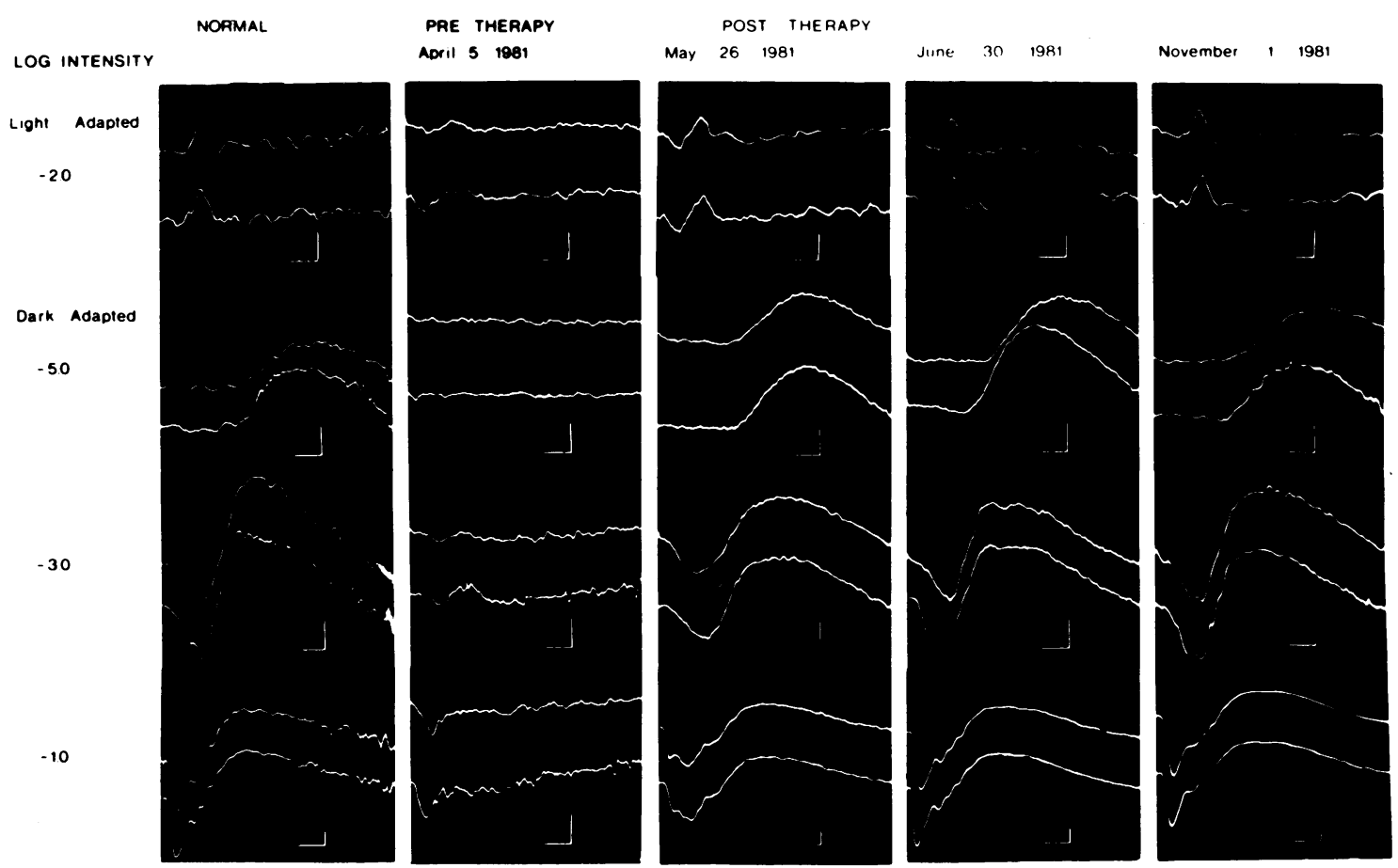

Fig. 1 Electroretinograms of a normal subject (1st column) and of the patient with vitamin A malabsorption. The patients responses were measured at different dates before (2nd column) and after (3rd-5th columns) therapy. The date of each examination is denoted above each column. The ERG responses were evoked by single white flashes of different intensities during the light- (1st row) and dark-adapted states (2nd-4th rows). The intensity of the test light is given as the density of the 'neutral' filter interposed in the light path. Two traces are shown for each intensity and date; the upper one was recorded from the left eye and the lower one from the right eye. The calibration marks have a height of $100 \mu v$ and a length of $25 \mathrm{~ms}$. 


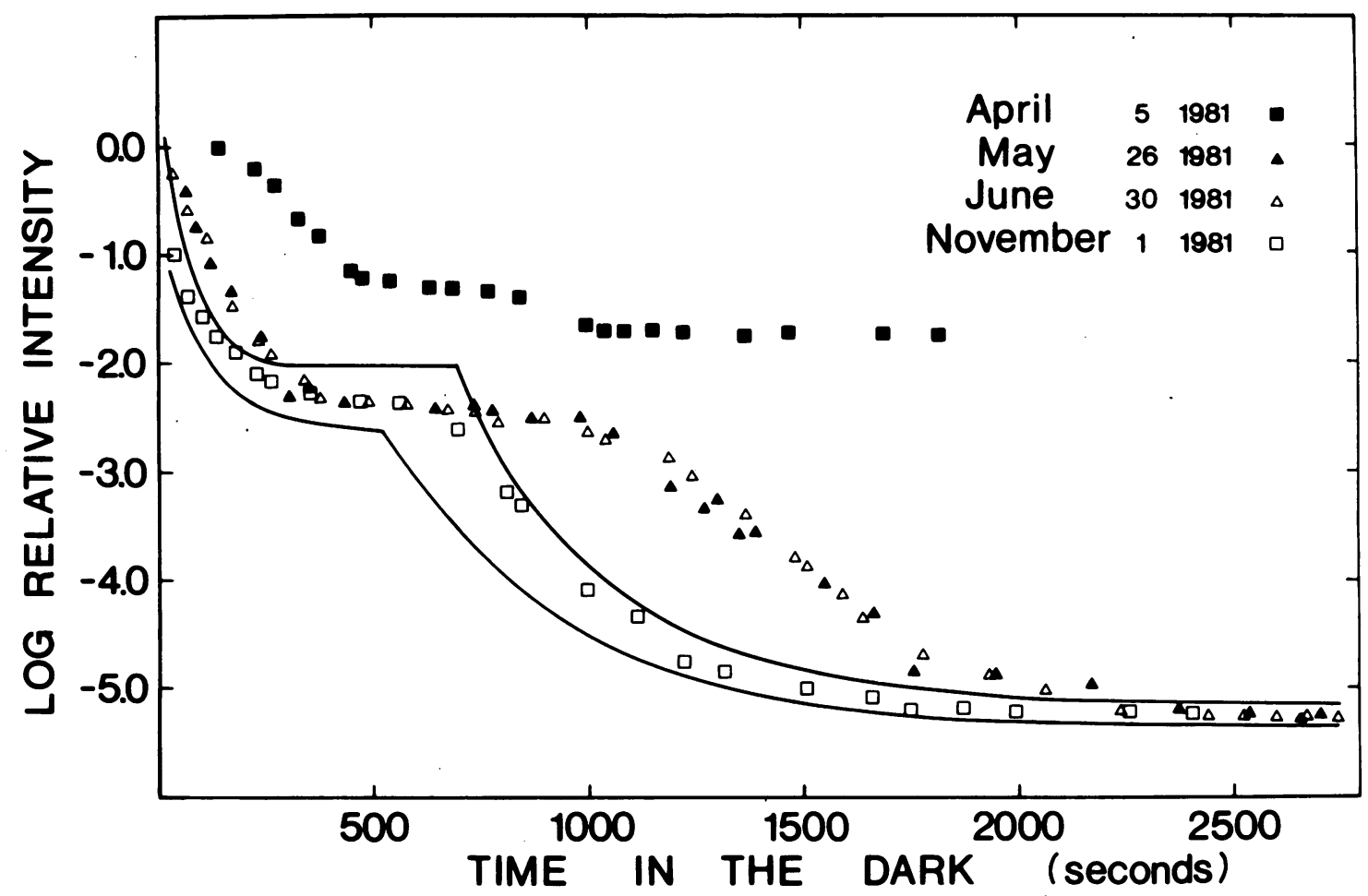

Fig. 2 Dark-adaptation curves measured with a blue-green test light $(500 \mathrm{~nm})$, subtending a visual angle of $2^{\circ}$, flashed on the temporal retina of the right eye $15^{\circ}$ from the fovea. The continuous curves describe the normal range (mean $\pm 2 S D$ ). The data points describe the log relative intensity needed for just seeing the test light as a function of time in the dark following an intense bleaching exposure. Four curves of the patient are shown measured at different times before (solid squares) and after (solid and open triangles, open squares) vitamin $A$ therapy.

after an intense bleaching exposure was determined psychophysically. ${ }^{15}$ All threshold measurements were done on the temporal retina of the right eye $15^{\circ}$ from the fovea. Threshold was measured with a $2^{\circ}$ field flashed for $100 \mathrm{~ms}$ every second. Visual threshold was defined as the light intensity needed for just seeing the flashing test light. During the course of dark adaptation, thresholds were measured intermittently with blue-green light $(500 \mathrm{~nm})$ and orange-red light $(600 \mathrm{~nm})$. This method was found to be useful for distinguishing between cone mediated and rod mediated vision.

\section{Results}

Fig. 1 compares ERG responses recorded from a normal subject (1st column) and from the vitamin A deficient patient before therapy (2nd column) and at different times after therapy (3rd, 4th, and 5th columns). The date at which each set of responses was recorded is denoted above the columns describing the patient's ERG responses. The illustrated responses were evoked in the light- (1st row) and dark-adapted (2nd-4th rows) states. The intensity of the light stimuli given as the density of the 'neutral' filter interposed in the light path is denoted at the left of each row of responses.

Fig. 2 describes the dark-adaptation curves of the patient measured at the same dates as the ERG responses (Fig. 1) were recorded. Each data point represents the log intensity needed for just seeing the test light as a function of time in the dark after an intense bleaching exposure. The 2 continuous curves describe the normal range (mean \pm 2 SD). ${ }^{15}$ A summary of the ERG and psychophysical data is given in Table 1.

Before therapeutic procedures were applied (2nd column-5 April 1981) the patient gave an undetectable rod response to a dim test flash (2nd row). As the test flash was made brighter, the dark-adapted ERG response increased slightly in amplitude, and with the brightest flash (4th row) the response was mainly composed of an a-wave and a very small bwave. This ERG pattern is reminiscent of the 
Table 1 Electroretinographical and psychophysical data of the vitamin A deficient patient before and after therapy

\begin{tabular}{|c|c|c|c|c|c|c|c|c|}
\hline & \multicolumn{2}{|c|}{ Dark adaptation } & \multicolumn{2}{|l|}{ Light adapted } & \multicolumn{4}{|c|}{$\begin{array}{l}\text { Electroretinogram: } \\
\text { Dark adapted }\end{array}$} \\
\hline & $\begin{array}{l}\text { Cone plateau } \\
\text { Log relative }\end{array}$ & $\begin{array}{l}\text { Rod plateau } \\
\text { intensity }\end{array}$ & $\begin{array}{l}\log I=-2 \cdot 0 \\
b-w a v e(\mu \nu)\end{array}$ & $\begin{array}{l}\log I=-5 \cdot 0 \\
b-w a v e(\mu v)\end{array}$ & \multicolumn{2}{|c|}{$\log I=-3 \cdot 0$} & \multicolumn{2}{|c|}{$\log I=-1 \cdot 0$} \\
\hline $\begin{array}{l}\text { Normal } \\
(\text { mean } \pm 2 \text { SD })\end{array}$ & $-2 \cdot 32 \pm 0 \cdot 28$ & $-5 \cdot 27 \pm 0 \cdot 10$ & $135 \pm 65$ & $205 \pm 95$ & $155 \pm 90$ & $480 \pm 130$ & $476 \pm 116$ & $758 \pm 135$ \\
\hline Pretherapy OD & & & 80 & Extinct & 50 & 70 & 120 & 100 \\
\hline 5 April 1981 O & $5^{-1 \cdot 40}$ & $-1 \cdot 76$ & 40 & Extinct & 30 & 40 & 100 & 70 \\
\hline Post-therapy OL & 0,30 & & 120 & 200 & 120 & 290 & 260 & 440 \\
\hline 26 May 1981 O & $5^{-2 \cdot 38}$ & & 90 & 160 & 140 & 300 & 300 & 460 \\
\hline 30 June OI & ) & 5.36 & 110 & 280 & 220 & 420 & 420 & 680 \\
\hline 1981 & & $-5 \cdot 26$ & 100 & 220 & 160 & 350 & 420 & 620 \\
\hline 1 Nov & )$_{-2.40}$ & -5.30 & 120 & 200 & 180 & 380 & 380 & 640 \\
\hline 1981 & & $-5 \cdot 20$ & 100 & 200 & 120 & 360 & 440 & 660 \\
\hline
\end{tabular}

Schubert-Bornschein type of night blindness. ${ }^{15-17}$ Such an ERG pattern, which is in contrast to the one recorded from a similar patient, ${ }^{5}$ implies that, in addition to the reduction in rod function, signal transmission from the rods to the proximal retina is affected. The cone responses recorded in the lightadapted state (1st row) were also affected by the vitamin A deficiency but to a lesser extent than were the rod responses. Similar results were previously reported in a case of alcoholic liver cirrhosis ${ }^{8}$ and in vitamin A deficiency due to jeujunoileal bypass. ${ }^{5}$ Although the amplitude of the light-adapted ERG was subnormal, the implicit time of the b-wave was within the normal range. The dark-adaptation curve measured on the same date (Fig. 2 solid squares) showed quantitatively the reduced retinal function. The cone sensitivity represented by the plateau of the first phase of threshold recovery was reduced by about $1 \cdot 0$ log units compared with the normal. Rod vision was depressed to a much greater extent, and at the end of the dark-adaptation period threshold it was elevated above the normal by as much as $3.6 \mathrm{log}$ units. Fifty-one days later, on 26 May 1981, the ERG responses (Fig. 1, 3rd column) and dark-adaptation curve (Fig. 2, solid triangles) were measured again. This examination was performed 48 days after the jeujunoileal bypass was surgically reversed and after the patient received a total of 5 injections of 100000 units of vitamin A each (one injection a week). The ERG responses improved significantly (Fig. 1, 3rd column). The light-adapted ERG was very close to the normal. However, the dark-adapted responses, especially those evoked by the bright stimuli, were still subnormal in amplitude. The dark-adaptation curve (Fig. 2, solid triangles) showed normal photopic sensitivity during the plateau of the first phase of threshold recovery and normal rod sensitivity at the end of the dark-adaptation process. However, the time course of threshold recovery was abnormal. The recovery of the photopic mechanism was slightly slower than the normal, while that of the scotopic mechanism was more severely delayed. After this examination vitamin A therapy was stopped. Thirtyfive days later, on 6 June 1981, the ERG responses elicited both in the light- and dark-adapted states had a normal pattern and amplitude (Fig. 1, 4th column), that is, a significant improvement compared with previous examination was observed. However, threshold recovery in the dark after an intense bleaching exposure (Fig. 2, open triangles) did not differ from the one measured before (Fig. 2, solid triangles), that is, visual sensitivity during the photopic and scotopic plateau was normal, but the rate of recovery was slower than normal. On 1 November 1981, after 5 months with no additional treatment, the ERG responses were normal (Fig. 1, 5th column), and the dark-adaptation curve was normal with regard to both sensitivity and rate of recovery (Fig. 2, open squares).

\section{Discussion}

The patient presented in this report suffered from vitamin A deficiency caused by malabsorption of fats and vitamins. The malabsorption was probably caused by the jeujunoileal bypass surgery performed about 11 years prior to her complaint about visual dysfunction. Malabsorption of fat soluble vitamins due to jeujunoileal bypass surgery has already been reported ${ }^{4}$ and further proved here by the Schilling test.

Retinal functions were measured electroretinographically and psychophysically to determine the selective effects of vitamin A deficiency on rods and cones and to follow the time course of recovery. Before therapy started the ERG responses indicated a severely depressed retinal function in the light- and dark-adapted states (Fig. 1, 2nd column). The electrical responses evoked in the dark-adapted state 
by bright stimuli had temporal characteristics and amplitudes similar to those measured in the lightadapted state, indicating that the damage to the rod system was greater than to the cone system. The dark-adaptation curve supported this interpretation (Fig. 2, solid squares). The deterioration in rod vision was more pronounced than the deterioration of cone vision. Thus it was concluded in agreement with previous reports that cones were more resistant than rods to the deleterious effects of vitamin A deficiency. ${ }^{358}$ Differential resistance of cones and rods was also found in the rat's retina to insults such as iodoacetate poisoning, ${ }^{18}$ light damage,${ }^{19}$ and retinal degeneration. ${ }^{2021}$ Thus it seems that the rods are in general more sensitive than the cones to retinopathic agents.

Although the electrophysiological and psychophysical measurements pointed to severe retinal damage, the recovery of retinal function was surprisingly fast. Retinal function expressed by the ERG responses recovered to the normal level within 86 days (Fig. 1, 4th column). The psychophysical threshold at the end of dark adaptation reached the normal level even faster (Fig. 2, solid triangles). Recovery in our patient was significantly slower than in a similar case previously reported. ${ }^{5}$ The difference may be due to the different time interval between the surgery and the evaluation of night vision, being 11 years in our patient and $3 \frac{1 / 2}{2}$ years in the previous report. ${ }^{5}$ However, the rate of recovery found here was significantly faster than that observed in most patients suffering from vitamin A deficiency due to cirrhosis of the liver ${ }^{38}$ Moreover, in patients with liver disease large doses of vitamin $\mathrm{A}$ had to be administered daily to regain night vision, ${ }^{38}$ and when therapy was discontinued retinal function started to decline. ${ }^{3}$ This is probably due to different causes of vitamin A deficiency.

The patient presented here also suffered from cirrhosis of the liver. However, the recovery of her night vision was very fast and required little additional vitamin A. Moreover, after the 2 nd examination (26 May 1981) vitamin A therapy was discontinued, yet her dark-adapted ERG responses continued to improve (Fig. 1). It was therefore assumed that the cause of night blindness was malabsorption while vitamin A metabolism was unharmed. Once absorption was allowed, the vitamin A stores of the body were rebuilt and night vision was regained. In the patients with alcoholic cirrhosis absorption in the intestine of fat soluble vitamins was probably normal, but vitamin A metabolism was defective, resulting in vitamin A deficiency and night blindness. In order to replenish the rhodopsin level in the retina large doses of vitamin $\mathrm{A}$ had to be administered continuously. ${ }^{38}$

The dark-adaptation curves illustrated in Fig. 2 indicate that, while rod sensitivity in the dark-adapted state reached the normal level shortly after therapy started, the time course of the recovery of rod vision was significantly delayed (solid and open triangles). Similarly delayed curves were reported in cases of cirrhosis of the liver in contrast to cases of obstructive jaundice. ${ }^{3}$ The delayed rod adaptation was explained by the defective vitamin A metabolism due to the liver disease, a phenomenon that was not seen when vitamin A deficiency resulted from malabsorption. ${ }^{3}$ It is possible that the delayed dark-adaptation curves found here were due to the cirrhosis of the liver. However, the observations that the ERG responses and the rate of rod adaptation reached the normal levels excluded such a possibility. It is therefore suggested that the extended period of vitamin A deficiency caused, in addition to the reduction in rhodopsin content, also some biochemical or functional damage to the rods. This damage resulted in either a delayed rate of rhodopsin synthesis or a stronger than normal effect of bleached rhodopsin on rod threshold. After the jeujunoileal bypass was reversed, vitamin A stores were replenished and the rhodopsin content of the rods in the dark-adapted state was normal. However, only later did the presence of an adequate supply of vitamin A restore the functional damage to the rods, and the rate of rod adaptation in the dark after a strong bleaching exposure reached the normal time course (Fig. 2, open squares).

In this study 2 different techniques, electrophysiological and psychophysical, were employed to measure the integrity of the visual system in the darkadapted state. However, ERG responses (Fig. 1) were not directly related to the psychophysical data (Fig. 2). On 26 May 1981 the dark-adapted rod threshold was normal, while the ERG responses were subnormal in amplitude. A month later (30 June 1981) there was no change in the dark-adaptation curve, but significant improvement in the ERG responses was observed. During the following 4 months there were no further changes either in the electrical responses of the eye or in the dark-adapted rod sensitivity to light. These findings support previous data showing that the recovery from a state of vitamin A deficiency was faster in the peripheral rods than in the perifoveal rods. ${ }^{8}$ Rod threshold was measured here psychophysically by a $2^{\circ}$ test light flashed on the temporal retina $15^{\circ}$ from the fovea. Thus it described scotopic activity in a local retinal area. The ERG described the activity of the entire retina. Shortly after therapy started the peripheral retina recovered, as expressed by the normal rod threshold in the dark-adapted state. However, more central rods had not yet fully recovered thus the ERG responses were subnormal. A month later all the rods had recovered, and 
therefore both the ERG responses and the psychophysically determined rod threshold were within the normal range.

\section{References}

1 Jale GE, Ourgaud AG, Baisinger LF, Holmes WD. Night vision. Springfield: Thomas, 1959.

2 Wilbur DL, Eusterman GB. Nutritional night blindness. Report of a case. JAMA 1934; 102: 364 .

3 Patek AJ Jr, Haig C. The occurrence of abnormal dark adaptation and its relation to vitamin A metabolism in patients with cirrhosis of the liver. J Clin Invest 1939; 18: 609-16.

4 Rogers EL, Douglas W, Russell RM, Bushman L, Hubbard TB, Iber FL. Deficiency of fat soluble vitamins after jeujunoileal bypass surgery for morbid obesity. Am J Clin Nutr 1980; 33: 1208-14.

5 Brown GC, Felton SM, Benson WE. Reversible night blindness associated with intestinal bypass surgery. Am J Ophthalmol 1980; 89: 776-9.

6 Carney EA, Russell RM. Correlation of dark-adaptation test results with serum vitamin A levels in diseased adults. J Nutr 1980; 110: 552-7.

7 Haig C. Hecht S, Patek AJ Jr. Vitamin A and rod-cone dark adaptation in cirrhosis of the liver. Science 1938; 87: 534-6.

8 Sandberg MA, Rosen JB, Berson EL. Cone and rod function in vitamin A deficiency with chronic alcoholism and in retinitis pigmentosa. Am J Ophthalmol 1977; 84: 658-64.
9 Wald G, Jeghers H, Arminio J. An experiment in human dietary night blindness. Am J Physiol 1938; 123: 732-46.

10 Hecht S. Mandelbaum J. Dark adaptation and experimental human vitamin A deficiency. Am J Physiol 1940; 130: 651-63.

11 Dowling JE, Wald G. Vitamin A deficiency and night blindness. Proc Natl Acad Sci USA 1958; 44: 648-61.

12 Dowling JE. Chemistry of visual adaptation in the rat. Nature 1960; 188: 114-8.

13 Auerbach E, Guggenheim K, Kaplansky J, Rowe H. Effect of protein depletion on the electric response of the retina in albino rats. J Physiol 1964; 172: 417-24.

14 Schneider B, Hood DC, Cohen H, Stampfer M. Behavioral threshold and rhodopsin content as a function of vitamin A deprivation in the rat. Vision Res 1977; 17: 799-806.

15 Perlman I, Haim T. Visual functions of a new type of night blindness. Invest Ophthalmol Visual Sci in press.

16 Schubert G, Bornschein H. Beitrag zur Analyse des menschlichen Elektroretinograms. Ophthalmologica 1952; 123: 396-413.

17 Auerbach E, Godel V, Rowe H. An electrophysiological and psychophysical study of two forms of congenital nyctalopia. Invest Ophthalmol Visual Sci 1969; 8: 332-45.

18 Noell WK. Cellular physiology of the retina. J Opt Soc Am 1963; 53: 36-48.

19 Cicerone CM. Cones survive rods in the light-damaged eye of the albino rats. Science 1976; 194: 1183-5.

20 Perlman I. Dark-adaptation in abnormal (RCS) rats studied electroretinographically. J Physiol 1978; 278: 161-75.

21 Cicerone CM, Green DG, Fisher LG. Cone input to ganglion cells in hereditary retinal degeneration. Science 1979; 203: 1113-5. 